\title{
Intermediate-term clinical outcomes of primary biventricular repair for left ventricular outflow tract obstruction and ventricular septal defect
}

\author{
Takaya Hoashi, MD, Edward L. Bove, MD, Eric J. Devaney, MD, Jennifer C. Hirsch, MD, and \\ Richard G. Ohye, MD
}

\begin{abstract}
Objective: Primary biventricular repair for left ventricular outflow tract obstruction and ventricular septal defect remains challenging. The intermediate-term outcomes and risk factors for mortality remain undefined.
\end{abstract}

\begin{abstract}
Methods: All patients undergoing primary biventricular repair of left ventricular outflow tract obstruction and ventricular septal defect from 1995 to 2008 at the C. S. Mott Children's Hospital, University of Michigan Health Systems were analyzed.
\end{abstract}

\begin{abstract}
Results: Thirty-one patients (mean age, 18 days; 20 male) with a median follow-up of 6.7 years (range, $0.3-13.5$ years) were identified. The ventricular septal defect was enlarged in 15 patients, and a limited atrial septal defect was constructed in 16 patients. There were 6 hospital and 2 late deaths. Ten-year patient survival was $72.3 \%$. Lower body weight $(P=.040)$, complete atrial septal defect closure $(P=.026)$, and longer cardiopulmonary bypass time $(P=.026)$ were risk factors of hospital mortality. An atrial septal defect was patent in 16 patients at discharge, 2 of whom required later surgical closure. Relief of recurrent left ventricular outflow tract obstruction was performed in 1 patient. No patient required pacemaker implantation. Five-year freedom from right ventricleto-pulmonary artery conduit replacement was $39.3 \%$. Smaller-sized conduit $(P=.020)$ and use of aortic allograft $(P=.048)$ were risk factors for early failure.
\end{abstract}

Conclusion: Primary biventricular repair for patients with left ventricular outflow tract obstruction and ventricular septal defect provides good early and intermediate-term outcomes. Maintaining a small atrial septal defect may improve hospital mortality. Selective ventricular septal defect enlargement and careful construction of the intraventricular pathway result in a low incidence of recurrent left ventricular outflow tract obstruction, as well as avoidance of heart block. Maximizing valve diameter and avoiding aortic allografts may lengthen conduit longevity. (J Thorac Cardiovasc Surg 2011;141:200-6)

The majority of patients born with significant left ventricular outflow tract obstruction (LVOTO) will have associated left ventricular hypoplasia and will require staged palliation to a Fontan procedure. However, a subset of these patients will also have a ventricular septal defect (VSD), providing an outlet for the left ventricle (LV) and allowing normal ventricular growth. In these patients with 2 adequately sized ventricles, biventricular repair can be undertaken, but remains challenging. The repair consists of the 2 main components. The first is the reconstruction of the aortic arch incorporating the native proximal pulmonary artery (PA) in the manner of a modified Norwood procedure. The second is rerouting the LV output from the VSD to the native

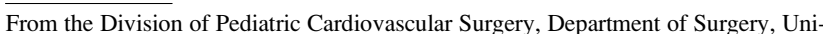
versity of Michigan Medical School, Ann Arbor, Mich.

Disclosures: Authors have nothing to disclose with regard to commercial support.

Received for publication Dec 16, 2009; revisions received April 2, 2010; accepted for publication June 6, 2010; available ahead of print July 12, 2010.

Address for reprints: Richard G. Ohye, MD, 5144 Cardiovascular Center/SPC 5864, 1500 East Medical Center Drive, Ann Arbor, MI 48109-5864 (E-mail: ohye@ umich.edu).

$0022-5223 / \$ 36.00$

Copyright (c) 2011 by The American Association for Thoracic Surgery doi:10.1016/j.jtcvs.2010.06.008 pulmonary valve with an intraventricular tunnel and creating a new connection between the right ventricle (RV) and PA with a conduit (Rastelli-type operation). ${ }^{1}$

There are 2 surgical strategies that can be used to achieve this goal. One approach is the 2-stage repair with an initial Norwood procedure, followed by a Rastelli-type biventricular repair. This approach was the first method used to treat these patients. ${ }^{2-4}$ More recently, primary repair, which avoids the interstage mortality, volume overload, and cyanosis caused by shunt-dependent physiology, has become the preferred method of repair at many centers. ${ }^{5-11}$ In 1999, we compared the early clinical outcomes of primary repair versus staged repair ${ }^{12}$ and demonstrated that the survival of those undergoing primary repair was comparable to the survival of those undergoing 2-stage repair. Since that time, several other reports have also shown the safety and effectiveness of this strategy. ${ }^{13,14}$

Although hospital survival and short-term outcomes are acceptable for primary repair, risk factors for mortality and longer-term results remain unknown. One late concern is the fate of the reconstructed LVOT. Primary repair requires the creation of an intraventricular pathway from the VSD to the native pulmonary valve (Rastelli-type procedure) to 

Abbreviations and Acronyms
ASD $=$ atrial septal defect
$\mathrm{LV}=$ left ventricle
LVOT = left ventricular outflow tract
LVOTO $=$ left ventricular outflow tract obstruction
$\mathrm{MV}=$ mitral valve
PA $=$ pulmonary artery
$\mathrm{RV} \quad=$ right ventricle
VSD $=$ ventricular septal defect

provide an outlet for the LV in the neonatal period. Longterm studies of patients with transposition of the great arteries undergoing the Rastelli procedure have shown an incidence of recurrent LVOTO. ${ }^{15}$ The other concern is the durability of an RV-to-PA conduit. Although several materials and technical modifications have been described, an ideal conduit for small-sized patients remains elusive. All patients undergoing placement of an RV-to-PA conduit in the neonatal period will ultimately require replacement. This study analyzed the risk factors for mortality and assessed the intermediate-term outcomes of primary repair.

\section{MATERIALS AND METHODS Patients}

Between 1995 and 2008, 31 patients with LVOTO and VSD underwent primary biventricular repair at C. S. Mott Children's Hospital, University of Michigan Health System (Table 1). Ten of these patients, who had undergone this procedure before 1999 , were included in the earlier report. ${ }^{12}$ Since then, we have used primary biventricular repair as the preferred strategy, and the latter 21 consecutive patients of this group underwent this approach. This study was approved by the University of Michigan Medical School Institutional Review Board for Human Subject Research.

\section{Operative Techniques}

There were 3 main methods of aortic arch reconstruction. Twelve patients underwent a Norwood-type arch reconstruction as previously described (Figure 1, A) ${ }^{16}$ Early in the experience, 12 patients with interrupted aortic arch type B underwent reverse-oriented direct anastomosis between the ascending and the descending aorta (Figure 1,B). For this technique, the ascending aorta was transected just above the sinotubular junction and the descending aorta was transected just distal to the ductus arteriosus. The back wall of the distal ascending aorta was then anastomosed directly to the back wall of the descending aorta, leaving an opening in the anastomosis inferiorly. The proximal ascending aorta was connected to the proximal main PA in an end-to-side or a side-by-side fashion. Next, a direct anastomosis between the proximal main PA and the reconstructed transverse arch was performed. The remaining 6 patients underwent direct anastomosis of the proximal main PA and the distal ascending aorta (Figure 1,C). For this technique, both the main PA and ascending aorta were divided just distal to the sinotubular junction. The distal ascending aorta and arch were augmented as necessary with cryopreserved pulmonary allograft. The distal ascending aorta was then anastomosed directly to the proximal main PA. The proximal end of the ascending aorta was connected to the main pulmonary trunk in an end-to side fashion. For both of the latter 2 techniques, a Lecompte maneuver was performed to facilitate reconstruction of the aortic arch and RV-to-PA conduit placement. ${ }^{17}$

Patients underwent the arch reconstruction with deep hypothermic circulatory arrest or regional cerebral perfusion, on the basis of a randomized trial ongoing during part of the experience. Standard methods were used for both techniques as previously described. ${ }^{18}$

After the arch reconstruction, a right ventriculotomy was performed. Through the right ventriculotomy, the VSD was closed with a polytetrafluoroethylene patch constructed to form an intraventricular pathway from the LV to the pulmonary valve (neoaortic valve) as in a typical Rastelli procedure. The VSD was enlarged anterosuperiorly at the discretion of the operating surgeon according to the intraoperative appearance. The atrial septal defect (ASD) was also closed or partially closed at the discretion of the operating surgeon. Delayed sternal closure was used in all patients.

\section{Data Collection and Statistical Analysis}

Preoperative and postoperative data were collected from the patients' medical records. The intermediate-term follow-up data were collected from the outpatient caregivers. Data are expressed as mean \pm standard deviation or as medians (range) as appropriate and were analyzed with Stat View (SAS Institute Inc, Cary, NC). Independent risk factors associated with hospital mortality were sought using logistic regression. Risk factors for hospital mortality identified by univariate analysis were selected for the multivariate analysis if there was no sizable direct correlation between these factors. Actuarial survival and freedom from RV-PA conduit replacement were estimated by the Kaplan-Meier method. Both the Cox proportional hazard regression analysis and log-rank test were applied to analyze the risk of RV-PA conduit replacement because of the differing follow-up periods.

\section{RESULTS \\ Patients}

Patient demographics are summarized in Table 1. The median follow-up period for all hospital survivors was 6.7 years (range, 0.3-13.5 years).

\section{Anatomic Features}

Preoperative diagnosis was based on transthoracic echocardiography. The aortic valve was atretic in 6 patients. The remaining 25 patients had aortic annulus hypoplasia $(4.2 \pm 0.6 \mathrm{~mm},-7.1 \pm 2.3 \mathrm{Z}), 13$ of whom had a bicuspid aortic valve. All patients had LVOTO with an apexforming LV. Transmitral valve mean inflow gradient of all patients was less than $4 \mathrm{~mm} \mathrm{Hg}$. The associated major extracardiac and cardiovascular malformations are listed in Table 1. All patients had both a patent ductus arteriosus and an ASD or patent foramen ovale. One patient with Taussig-Bing anomaly and aortic atresia had undergone bilateral PA banding before transfer to the University of Michigan Medical School. No patient underwent balloon aortic valvuloplasty before operation.

\section{Operative Techniques}

Mean cardiopulmonary bypass time, aortic crossclamp time, and regional cerebral perfusion/deep hypothermic circulatory arrest times are listed in Table 2. Regional cerebral perfusion was used in 8 patients, and deep 
TABLE 1. Patient characteristics

\begin{tabular}{lc}
\hline \multicolumn{1}{c}{ Patient population $(\mathbf{n}=\mathbf{3 1})$} & \\
\hline Patient characteristics & $20: 11$ \\
Male:female $(\mathrm{n})$ & $18.2 \pm 20.4$ \\
Age at operation $(\mathrm{d}$, mean $\pm \mathrm{SD})$ & $3.3 \pm 0.6$ \\
Body weight at operation $(\mathrm{kg}$, mean $\pm \mathrm{SD})$ & $0.21 \pm 0.02$ \\
Body surface area at operation $\left(\mathrm{m}^{2}\right.$, mean $\left.\pm \mathrm{SD}\right)$ & 3 \\
Gestational age $<38$ wk $(\mathrm{n})$ & 15 \\
Major extracardiac abnormality $(\mathrm{n})$ & 13 \\
$\quad$ DiGeorge syndrome & 2 \\
CHARGE association & \\
Cardiac anatomy (n) & \\
Aortic valve & 6 \\
Atresia & 25 \\
Hypoplastic & \\
Aortic valve morphology & 13 \\
Bicuspid & 4 \\
Tricuspid & \\
Associated cardiac anomalies & 23 \\
Interrupted aortic arch & 1 \\
Type A & 20 \\
Type B & 2 \\
Type C & \\
Coarctation of the aorta with hypoplastic aortic arch & 4 \\
Double outlet right ventricle with aortic atresia & 1 \\
Aortopulmonary window & 1 \\
Aberrant right subclavian artery & 8 \\
Anomalous coronary artery & 5 \\
Left superior vena cava & 1 \\
Right aortic arch & \\
Dextrocardia & \\
\hline & \\
Strat & \\
\hline
\end{tabular}

$S D$, Standard deviation.

hypothermic circulatory arrest was used in the remaining 23 patients.

The VSD was enlarged in 15 patients to ensure an unobstructed left ventricular outflow tract (LVOT) pathway. For reconstruction of $\mathrm{RV}$-to-PA continuity, various types of conduit were inserted, as summarized in Table 2. The mean conduit diameter was $11 \pm 1.6$ (range, 8-14) $\mathrm{mm}$ in 16 of 31 patients $(52 \%)$. An atrial level shunt (patent foramen ovale or partially closed ASD) was left at the time of operation in 16 patients $(52 \%)$ at the discretion of the operating surgeon.

\section{Early Outcome and Mortality In Hospital}

Hospital survival was $80.6 \%$ (25/31 patients). The mean durations of postoperative ventilator support, intensive care unit stay, and hospital stay of all hospital survivors were $11.4 \pm 8.7$ days, $14.7 \pm 9.6$ days, and $26.3 \pm 12.8$ days, respectively.

Postoperative complications were low cardiac output syndrome requiring extracorporeal membrane oxygenation support in 3 patients (all hospital mortalities), mediastinitis in 2 patients (including 1 hospital mortality), arrhythmias in 3 patients (including 1 hospital mortality), prolonged ventilator support in 3 patients, chylothorax in 2 patients, thromboembolic event in 2 patients, graft-versus-host disease in 1 patient (hospital mortality), seizure in 1 patient, necrotizing enterocolitis in 1 patient, and hemi-diaphragm paralysis in 1 patient.

Echocardiography at discharge demonstrated a patent atrial level shunt in 16 patients (left to right in 8 patients, right to left in 1 patient, and bidirectional in 7 patients) with a mean percutaneous oxygen saturation on room air at discharge of $94.3 \% \pm 2.9 \%$ (range, $90 \%-99 \%$ ). Other echocardiographic findings at discharge were RV-to-PA conduit insufficiency more than mild in 10 patients $(40 \%)$, branch PA stenosis in 6 patients $(24 \%)$, and tricuspid valve insufficiency more than mild in 5 patients $(20 \%)$. All patients with branch PA stenosis had undergone a Lecompte maneuver. No patients demonstrated an RV-to-PA conduit gradient of more than $20 \mathrm{~mm} \mathrm{Hg}$, more than trivial ventricular level shunting by Doppler echocardiography, a pressure gradient across the LVOT, neoaortic valve insufficiency of more than mild, heart block requiring pacemaker implantation, or depressed LV systolic function.

Univariate analysis identified that body weight and body surface area at operation, complete ASD closure, and cardiopulmonary bypass time were significant risk factors of hospital mortality (Table 3). Multivariate analysis identified none of these variants as independent risk factors.

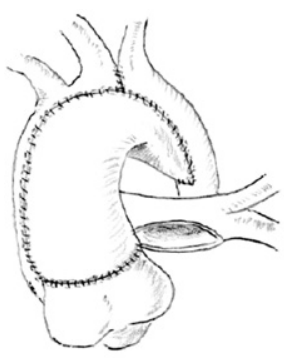

A

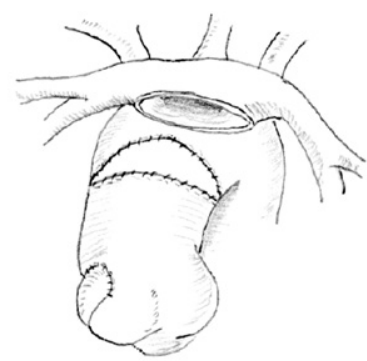

B

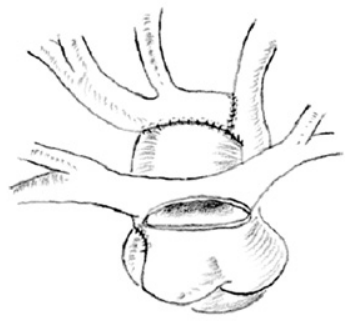

C

FIGURE 1. Three types of operative methods for aortic arch reconstruction. A, Norwood-type reconstruction. B, Reverse-oriented direct anastomosis. C, Direct anastomosis. 
TABLE 2. Perioperative data

\begin{tabular}{lc}
\hline \multicolumn{1}{c}{ Perioperative data $(\mathbf{n}=\mathbf{3 1})$} & \\
\hline Operative data (mean \pm SD) & $131 \pm 36$ \\
Cardiopulmonary bypass time & $79 \pm 13$ \\
Aortic crossclamp time & $40 \pm 4$ \\
Regional cerebral perfusion time $(\mathrm{n}=8)$ & $41 \pm 24$ \\
Circulatory arrest time $(\mathrm{n}=23)$ & \\
Operative method (n) & \\
Aortic arch reconstruction & 12 \\
$\quad$ Norwood-type & 12 \\
$\quad$ Reversed-oriented direct anastomosis & 6 \\
$\quad$ Direct anastomosis & 1 \\
$\quad$ Interposition graft & \\
Right ventricle-to-pulmonary artery & 14 \\
$\quad$ conduit materials & 8 \\
Cryopreserved pulmonary allograft & 4 \\
Cryopreserved aortic allograft & 3 \\
Contegra pulmonary valved conduit* & 2 \\
$\quad$ Shelhigh pulmonic valve conduit $\dagger$ & 17 \\
$\quad$ Hancock valved conduit $\dagger$ & 15 \\
Lecompte maneuver & 7 \\
ASD completely closed & \\
Subclavian artery division & \\
*Medtronic Inc, Minneapolis, Minn. $\dagger$ Shelhigh Inc, Union, NJ. $\ddagger$ Medtronic, Inc. \\
$S D$, Standard deviation; ASD, atrial septal defect.
\end{tabular}

\section{Late Outcomes}

Intermediate-term follow-up data collection was complete in 22 of 25 hospital survivors (88\%) (Table 4). Patient survival at 10 years was $72.3 \%$.

Intervention for branch PA stenosis was performed in 5 patients $(25 \%)$. All of the patients requiring reintervention on the branch PAs underwent a Lecompte maneuver at the primary operation. Residual aortic arch obstruction of more than $30 \mathrm{~mm} \mathrm{Hg}$ developed in 3 patients. These patients underwent patch augmentation or balloon angioplasty at 5.8, 6.3, and 7.5 months after the primary operation, which resulted in successful relief of the pressure gradient. Postoperative relief of recurrent LVOTO was required in only 1 patient. No patient required permanent pacemaker implantation.

Actuarial freedom from RV-PA conduit replacement at 1, 3 , and 5 years after operation was $87.1 \%, 54.2 \%$, and $39.3 \%$, respectively (Figure 2, A). Cox's proportional hazards models identified that smaller conduit size were significant risk factors of early conduit failure $(P=.020)$ (Figure 2, B). Log-rank test identified that aortic allograft failed earlier than pulmonary allograft $(P=.048)$ (Figure 2,C).

\section{DISCUSSION}

This study of the early and intermediate-term clinical outcomes of primary biventricular repair for 31 consecutive patients with VSD and LVOTO reveals that primary biventricular repair can be performed with good survival. Significant risk factors for hospital mortality on univariate analysis were lower body weight at operation, complete closure of atrial level shunt, and longer cardiopulmonary bypass time. Most likely because of sample size, none of these variables could be identified as independent risk factors on multivariable logistic analysis.

Our strategy of management for LVOTO and VSD with an adequately sized LV is as follows. If a patient has an aortic valve of good size and the obstruction is subvalvar, the VSD is closed primarily and a septal myectomy-myotomy is performed to relieve the subaortic stenosis. If the aortic valve is too small to function as the systemic semilunar valve, the native pulmonary valve is used as the neoaortic valve by 1 of 2 methods. In the presence of an adequately sized VSD, we prefer a Rastelli-type operation. This general preference is also because there is often extension of the

TABLE 3. Risk factor analysis for hospital mortality

\begin{tabular}{|c|c|c|c|c|c|c|c|c|}
\hline \multirow[b]{2}{*}{ Variable } & \multirow[b]{2}{*}{ Expired $(n=6)$} & \multirow[b]{2}{*}{ Survived $(n=25)$} & \multicolumn{3}{|c|}{ Univariate } & \multicolumn{3}{|c|}{ Multivariate } \\
\hline & & & $\boldsymbol{P}$ & Odds ratio & $95 \%$ CI & $P$ & Odds ratio & $95 \%$ CI \\
\hline BW at operation $(\mathrm{kg})$ & $2.70 \pm 0.51$ & $3.45 \pm .46$ & .040 & 0.12 & $0.0-0.9$ & .057 & 0.28 & $0.04-1.88$ \\
\hline Complete ASD closure (n) & $6 / 6$ & $9 / 25$ & .026 & 13.1 & $1.4-126.3$ & .997 & 4.6 & $0.36-60.0$ \\
\hline CPB time $(\min )$ & $159 \pm 40$ & $121 \pm 32$ & .026 & 1.003 & $1.0-1.6$ & $>.238$ & 1.00 & $0.99-1.06$ \\
\hline $\operatorname{AVD}(Z)$ & $-5.8 \pm 2.2$ & $-7.4 \pm 2.3$ & .180 & & & & & \\
\hline Lecompte maneuver (n) & $2 / 6$ & $15 / 25$ & .253 & & & & & \\
\hline Male (n) & $5 / 6$ & $15 / 25$ & 0.299 & & & & & \\
\hline AXC time (min) & $83.8 \pm 6.6$ & $78.1 \pm 13.8$ & .337 & & & & & \\
\hline Age at operation (d) & $24.8 \pm 22.7$ & $16.6 \pm 20.0$ & .382 & & & & & \\
\hline $\operatorname{AVD}(\mathrm{mm})$ & $4.4 \pm 0.7$ & $4.1 \pm 0.6$ & .438 & & & & & \\
\hline Conduit size (mm) & $10.7 \pm 1.4$ & $11.2 \pm 1.7$ & .526 & & & & & \\
\hline $\begin{array}{l}\text { Norwood arch } \\
\quad \text { reconstruction (n) }\end{array}$ & $3 / 6$ & $9 / 25$ & .543 & & & & & \\
\hline Coronary anomaly (n) & $1 / 6$ & $6 / 25$ & .711 & & & & & \\
\hline VSD enlargement & $2 / 6$ & $15 / 25$ & .933 & & & & & \\
\hline
\end{tabular}

$C I$, Confidence interval; $B W$, body weight; $B S A$, body surface area; $A S D$, atrial septal defect; $C P B$, cardiopulmonary bypass; $A V D$, aortic valve diameter; $A X C$, aortic crossclamp; $V S D$, ventricular septal defect. 
TABLE 4. Surgical and catheter-based interventions

\begin{tabular}{lrc}
\hline \multicolumn{1}{c}{ Procedure } & $\mathbf{n}$ & $(\%)$ \\
\hline RV-to-PA conduit replacement & 13 & $(59.1)$ \\
Repair of branch PA stenosis & 5 & $(22.7)$ \\
Repair of VSD patch leak & 3 & $(13.6)$ \\
Patch augmentation/balloon angioplasty & 3 & $(13.6)$ \\
$\quad$ for arch obstruction & & \\
Residual ASD closure & 2 & $(9.1)$ \\
Repair of recurrent LVOTO & 1 & $(4.5)$ \\
Patch exclusion of LVOT aneurysm & 1 & $(4.5)$ \\
\hline
\end{tabular}

$R V$, Right ventricle; $P A$, pulmonary artery; $V S D$, ventricular septal defect $\angle V O T O$, left ventricular outflow tract obstruction; $A S D$, atrial septal defect; $L V O T$, left ventricular outflow tract.

VSD to the outlet, complicating the harvesting of the pulmonary autograft with a circumferential rim of muscle. In contrast, if the VSD is small or not present, we use a Ross-Konno procedure and VSD closure. During the study period, no patients with LVOTO and VSD underwent a Ross-Konno procedure and VSD closure during the neonatal or early infant period at the University of Michigan Medical School. This is perhaps not surprising because most patients with significant LVOTO and a restrictive or absent VSD will also develop LV hypoplasia and not be a candidate for biventricular repair.

It is difficult to address the absolute subaortic diameter that separates critical and non-critical LVOTO, and this study was not designed to answer this question. In clinical practice, we do not use any formula or absolute or normalized measurements to definitively determine which patients have an inadequate LVOT. These decisions were made on the basis of the experience of the operating surgeon and the other members of the management team.

Of these risk factors, management of the ASD can be easily altered at the time of operation. For this operation, several surgical factors may affect the RV function in the early postoperative phase. First, an anterior right ventricular incision is required for better inspection to perform intraventricular rerouting and to set the RV-PA conduit as large as possible. Second, creation of the intraventricular pathway without LVOTO tends to reduce the effective right ventricular volume. Also, the use of cardiopulmonary bypass time can cause acute myocardial dysfunction and increase pulmonary vascular resistance postoperatively. These negative right-

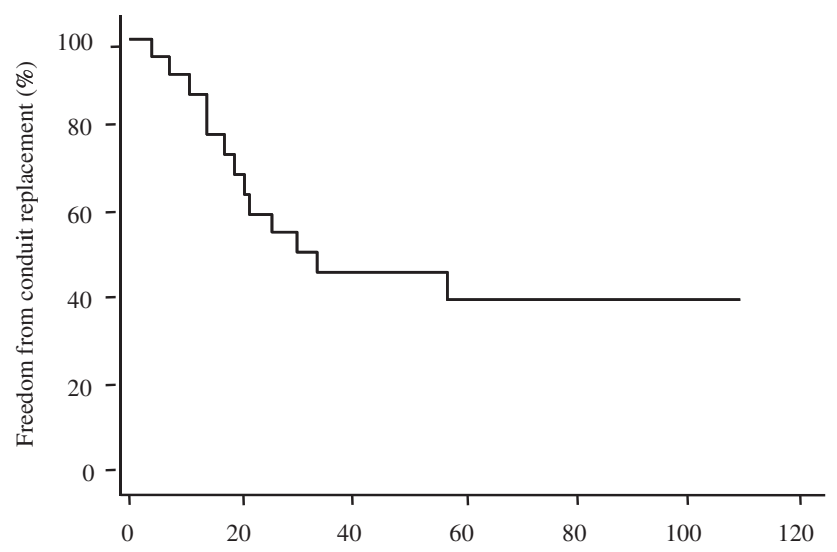

A
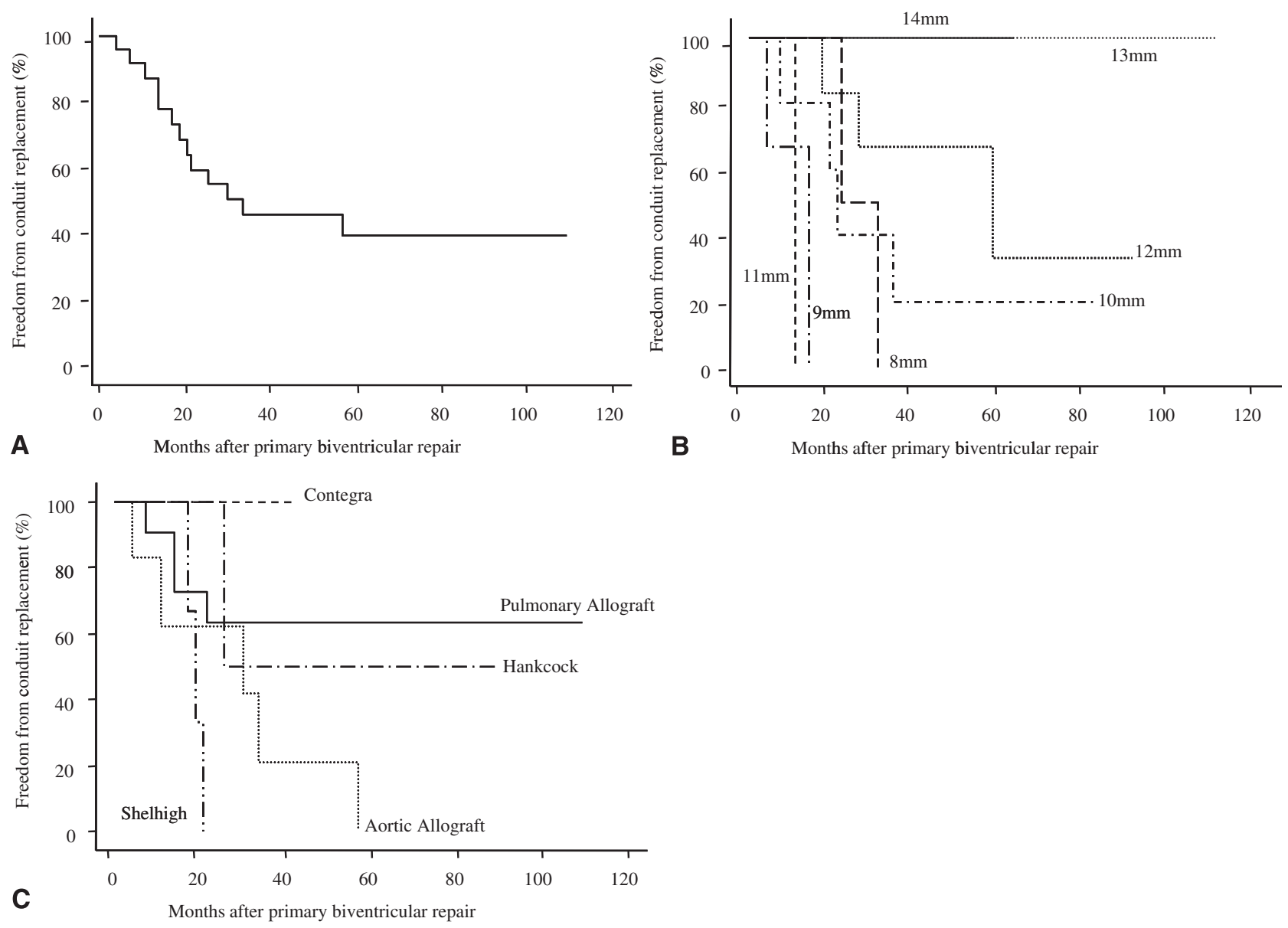

FIGURE 2. Actuarial freedom from conduit replacement for the entire cohort (A), subgroups of conduit size (B), and subgroups of conduit material (C). 
sided hemodynamic effects of the operation may be mitigated by the presence of an atrial level shunt. Indeed, most of the atrial shunts were patent at discharge, half of them demonstrating bidirectional or right-to-left shunting. In addition, in the setting of the development of late branch PA or RV-to-PA conduit stenosis or conduit insufficiency, the ability to shunt right to left may be protective. Those subjects who were discharged with left-to-right shunting may have represented patients with greater degrees of mitral valve (MV) hypoplasia, decreased LV compliance, or the normal physiologically higher left atrial pressure relative to right atrial pressure. Although the closure of a residual atrial level shunt was ultimately required in 2 of 16 patients, the remaining patients showed no shunting at late follow-up.

In our cohort, only 1 subject had an MV inflow gradient, measured at $4 \mathrm{~mm} \mathrm{Hg}$ by Doppler echocardiography. This subject had only a small patent foramen ovale, making the interpretation of the gradient more straightforward. However, determining the adequacy of the MV on the basis of the inflow gradient can be problematic in the face of a nonrestrictive or mildly restrictive atrial level shunt, as was the case in many of the subjects in this study. In these cases, we rely on the diameter and z-values of the MV annulus, as well as the morphology of the valve leaflets (eg, good excursion vs limited opening, thickened leaflets vs thin, mobile leaflets) and papillary muscles (single, dominant, closely spaced, or normal) to make a clinically based decision, along with the inflow gradients. All of the patients in this study were deemed to have an adequate MV and reasonable $\mathrm{z}$-values (range, -0.8 to -2.3 ). In addition, we tolerate some degree of potential MV hypoplasia, because there is evidence that the MV, as well as the LV, will demonstrate good potential for growth after repair. ${ }^{19}$

Our series also demonstrated that postoperative LVOTO was rare. Kreutzer and colleagues ${ }^{15}$ reported that freedom from reintervention for LVOTO was $88 \%$ at 5 years for the Rastelli procedure for dextro-transposition of the great arteries with VSD and LVOTO. They also noted that time to LVOTO reintervention was shorter for patients undergoing a Rastelli repair at less than 1 year of age. Postoperative LVOTO occurred in only 1 patient $(4 \%)$ in the current study. It is likely that a low threshold for VSD enlargement, performed in half of all patients, and careful construction of the LVOT baffle contributed to the low occurrence of LVOTO.

Although enlargement of the VSD may be effective in helping to prevent late LVOTO, there is risk of damage to the conduction system or injury to the septal perforating arteries. ${ }^{20}$ However, in this series, no patients required postoperative permanent pacemaker implantation, and all patients were discharged with normal ventricular function. Enlargement of the VSD in a superior and anterior direction avoids aortic valve conduction injury because the connecting bundle in this anatomic group is theoretically located posteroinferiorly.
In our previous study, we frequently used the Lecompte maneuver to facilitate the posterior reconstruction of the aorta to decrease the distance for the RV-to-PA conduit from the anteriorly located RV to the posterior pulmonary bifurcatio, and to facilitate later RV-to-PA conduit replacements. ${ }^{12}$ However, our ongoing experience, as presented in this article, revealed a higher incidence of branch PA stenosis with this maneuver. In addition, our technique has evolved to primarily using a Norwood-type repair technique for the aortic reconstruction. This technique, as opposed to the others described, tends to create a larger, more anteriorly situated neoaorta. This arrangement is also less favorable for the Lecompte maneuver. Our current preference is to perform the RV-to-PA conduit in the standard fashion more commonly associated with the typical Rastelli procedure.

The problem of conduit durability remains unsolved for all pediatric patients because of the lack of growth potential in the currently available options. However, some conduits may perform better than others. In the current study, aortic allografts and smaller-sized conduit were found to be inferior, as previously reported by others. ${ }^{21-23}$ Pulmonary allografts were preferentially used during the majority of the time interval of this study, including the use of bicuspidized grafts as necessary when an appropriately sized allograft was not available. ${ }^{24}$ Although the long-term durability is still unknown, the Contegra (Medtronic Inc, Minneapolis, MN) bovine jugular vein conduit, which is readily available in a variety of pediatric sizes, may also be a good alternative to pulmonary allograft. ${ }^{25}$

\section{CONCLUSIONS}

Our analysis of the early and intermediate-term clinical outcomes of primary biventricular repair for patients with LVOTO with VSD demonstrates good results. Maintaining a small degree of atrial level shunting may improve hospital mortality. Selected VSD enlargement and careful construction of the intraventricular pathway result in a low incidence of recurrent LVOTO, as well as avoidance of heart block. Although all RV-PA conduits will eventually require replacement in this young cohort of patients, maximizing valve diameter and avoiding the use of aortic allografts may lengthen conduit longevity.

\section{References}

1. Rastelli GC, McGoon DC, Wallace RB. Anatomic correction of transposition of the great arteries with ventricular septal defect and subpulmonary stenosis. J Thorac Cardiovasc Surg. 1969;58:545-52.

2. Norwood WI, Stellin GJ. Aortic atresia with interrupted aortic arch: reparative operation. J Thorac Cardiovasc Surg. 1981;81:239-44.

3. Gandhi SK, Siewers RD, Pigula FA. Complete surgical repair of aortic atresia with a normal left ventricle. Ann Thorac Surg. 2000;70:2145-7.

4. Erez E, Tam VK, Kanter KR, Fyfe DA. Successful biventricular repair after initial Norwood operation for interrupted aortic arch with severe left ventricular outflow tract obstruction. Ann Thorac Surg. 2001;71:1974-7.

5. Yasui H, Kado H, Nakano E, Yonenaga K, Mitani A, Tomita Y, et al. Primary repair of interrupted aortic arch and severe aortic stenosis in neonates. $J$ Thorac Cardiovasc Surg. 1987;93:539-45. 
6. Austin EH, Jonas RA, Mayer JE, Castaneda AR. Aortic atresia with normal left ventricle. Single-stage repair in the neonate. J Thorac Cardiovasc Surg. 1989; 97:392-5.

7. Serraf A, Bruniaux J, Lebidois J, Lacour-Gayet F, Kachaner J, Planche C. Aortic atresia with normal left ventricle. Ann Thorac Surg. 1991;51:1017-9.

8. Bogers AJ, Sreeram N, Hess J, Sutherland GR, Quaegebeur JM. Aortic atresia with normal left ventricle: one-stage repair in early infancy. Ann Thorac Surg. 1991;51:312-4.

9. Francois K, Dollery C, Elliott MJ. Aortic atresia with ventricular septal defect and normal left ventricle: one-stage correction in the neonate. Ann Thorac Surg. 1994; 58:878-80.

10. Black MD, Smallhorn JF, Freedom RM. Aortic atresia with a ventricular septal defect: modified single-stage neonatal biventricular repair. Ann Thorac Surg. 1999;67:751-5

11. Pearl JM, Cripe LW, Manning PB. Biventricular repair after Norwood palliation. Ann Thorac Surg. 2003;75:132-7.

12. Ohye RG, Kagisaki K, Lee LA, Mosca RS, Goldberg CS, Bové EL. Biventricular repair for aortic atresia or hypoplasia and ventricular septal defect. J Thorac Cardiovasc Surg. 1999;118:648-53.

13. Gruber PJ, Fuller S, Cleaver KM, Abdullah I, Gruber SB, Nicolson SC, et al. Early results of single-stage biventricular repair of severe aortic hypoplasia or atresia with ventricular septal defect and normal left ventricle. $J$ Thorac Cardiovasc Surg. 2006;132:260-3.

14. Nathan M, Rimmer D, del Nido PJ, Mayer JE, Bacha EA, Shin A, et al. Aortic atresia or severe left ventricular outflow tract obstruction with ventricular septal defect: results of primary biventricular repair in neonates. Ann Thorac Surg. 2006;82:2227-32.

15. Kreutzer C, De Vive J, Oppido G, Kreutzer J, Gauvreau K, Freed M, et al. Twentyfive-year experience with Rastelli repair for transposition of the great arteries. J Thorac Cardiovasc Surg. 2000;120:211-23.
16. Pigott JD, Murphy JD, Barber G, Norwood WI. Palliative reconstructive surgery for hypoplastic left heart syndrome. Ann Thorac Surg. 1988;45:122-8.

17. Lecompte Y, Zannini L, Hazan E, et al. Anatomic correction of transposition of the great arteries. J Thorac Cardiovasc Surg. 1981;82:629-31.

18. Goldberg CS, Bove EL, Devaney EJ, Mollen E, Schwartz E, Tindall S, et al. A randomized clinical trial of regional cerebral perfusion versus deep hypothermic circulatory arrest: outcomes for infants with functional single ventricle. J Thorac Cardiovasc Surg. 2007;133:880-7.

19. McElhinney DB, Lock JE, Keane JF, Moran AM, Colan SD. Left heart growth, function, and reintervention after balloon aortic valvuloplasty for neonatal aortic stenosis. Circulation. 2005;111:451-8.

20. Hörer J, Schreiber C, Dworak E, Cleuziou J, Prodan Z, Vogt M, et al. Long-term results after the Rastelli repair for transposition of the great arteries. Ann Thorac Surg. 2007;83:2169-75.

21. Niwaya K, Knott-Craig CJ, Lane MM, Chandrasekaren K, Overholt ED, Elkins RC. Cryopreserved homograft valves in the pulmonary position: risk analysis for intermediate-term failure. J Thorac Cardiovasc Surg. 1999;117:141-6.

22. Brown JW, Ruzmetov M, Rodefeld MD, Vijay P, Turrentine MW. Right ventricular outflow tract reconstruction with an allograft conduit in non-Ross patients: risk factors for allograft dysfunction and failure. Ann Thorac Surg. 2005;80:655-63.

23. Karamlou T, Blackstone EH, Hawkins JA, Jacobs ML, Kanter KR, Brown JW, et al. Can pulmonary conduit dysfunction and failure be reduced in infants and children less than age 2 years at initial implantation? J Thorac Cardiovasc Surg. 2006;132:829-38.

24. Michler RE, Chen JM, Quaegebeur JM. Novel technique for extending the use of allografts in cardiac operations. Ann Thorac Surg. 1994;57:83-7.

25. Brown JW, Ruzmetov M, Rodefeld MD, Vijay P, Darragh RK. Valved bovine jugular vein conduits for right ventricular outflow tract reconstruction in children: an attractive alternative to pulmonary homograft. Ann Thorac Surg. 2006;82: 909-16. 